\title{
Malignancy after lung transplantation
}

\author{
Osnat Shtraichman ${ }^{1,2}$, Vivek N. Ahya ${ }^{1}$ \\ ${ }^{1}$ Pulmonary, Allergy and Critical Care Division, Perelman School of Medicine, University of Pennsylvania, Philadelphia, PA, USA; ${ }^{2}$ Pulmonary \\ Institute, Rabin Medical Center, Affiliated with Sackler School of Medicine Tel Aviv University, Petach Tikva, Israel \\ Contributions: (I) Conception and design: All authors; (II) Administrative support: All authors; (III) Provision of study materials or patients: All \\ authors; (IV) Collection and assembly of data: All authors; (V) Data analysis and interpretation: All authors; (VI) Manuscript writing: All authors; (VII) \\ Final approval of manuscript: All authors. \\ Correspondence to: Vivek N. Ahya, MD, MBA. Associate Professor of Medicine, Vice Chief, Clinical Affairs, Pulmonary, Allergy \& Critical Care \\ Division, Perelman School of Medicine at the University of Pennsylvania, 9035 Gates Bldg., 3400 Spruce Street, Philadelphia, PA 19104, USA. \\ Email: Vivek.Ahya@uphs.upenn.edu.
}

\begin{abstract}
Lung transplantation is an established therapeutic option for selected patients with advanced lung diseases. As early outcomes after lung transplantation have improved, chronic medical illnesses have emerged as significant obstacles to long-term survival. Among them is post-transplant malignancy, currently representing the $2^{\text {nd }}$ most common cause of death 5-10 years after transplantation. Chronic immunosuppressive therapy and resulting impairment of anti-tumor immune surveillance is thought to have a central role in cancer development after solid organ transplantation (SOT). Lung transplant recipients receive more immunosuppression than other SOT populations, likely contributing to even higher risk of cancer among this group. The most common cancers in lung transplant recipients are non-melanoma skin cancers, followed by lung cancer and post-transplant lymphoproliferative disorder (PTLD). The purpose of this review is to outline the common malignancies following lung transplant, their risk factors, prognosis and current means for both prevention and treatment.
\end{abstract}

Keywords: Lung transplant; malignancy; immunosuppression; risk factors

Submitted Nov 16, 2019. Accepted for publication Feb 19, 2020.

doi: $10.21037 /$ atm.2020.02.126

View this article at: http://dx.doi.org/10.21037/atm.2020.02.126

\section{Introduction}

Outcomes after lung transplantation have steadily improved since Dr. Hardy's first attempt more than 50-years ago (1). While initially considered to be a rare, extreme surgical intervention, lung transplantation is now an established therapeutic option for selected patients with advanced lung diseases. It is a procedure after which short and intermediate-term survival is now commonplace with increasing numbers of patients achieving long-term survival with median survival approaching 7 -year in the current era (2). As outcomes have improved, chronic lung allograft dysfunction (CLAD) and chronic medical illnesses have emerged as a major obstacle to long-term survival. The focus of this review is on one of these major medical illnesses: malignancy after lung transplantation.

Transplant recipients have significantly higher rates for developing cancer than the general population (3). When cancers are found, treatment is often difficult and prognosis may be worse. In fact, in the most recent report of the International Society for Heart and Lung Transplantation (ISHLT), cancer represented the $2^{\text {nd }}$ most common cause of death in lung transplant recipients five to ten years out from transplant $(17.3 \%)$ and for patients who were more than 10 -year after the procedure (17.9\%) (2).

The necessary requirement for post-transplant chronic immunosuppressive therapy and resulting impairment of anti-tumor immune surveillance and anti-viral activity is thought to have a central role in cancer development (4). Induction agents that deplete T-lymphocytes in particular 
have been associated with increased risk of cancer after solid organ transplantation (SOT) (5). In the setting of impaired cell-mediated immunity, oncogenic viruses such as EpsteinBarr virus (EBV), human papilloma virus (HPV) and others have emerged as major risk factors for cancer development $(4,6)$. Various immunosuppressive agents/regimens may also directly impact cancer risk that is independent of their effects on the overall level of immunosuppression. For example, reports suggest that azathioprine is associated with increased risk for skin cancer, while mycophenolate mofetil (MMF) is not. A recent study showed that switching azathioprine to MMF resulted in a reduced risk of squamous cell skin carcinoma (7). While the mechanism is not well understood, azathioprine appears to have photosensitizing properties that have direct mutagenic effects (8). In contrast, mammalian target of rapamycin (mTOR) inhibitors may interfere with cancer cell proliferation and angiogenesis and have been associated with lower incidence of certain cancers such as Kaposi's sarcoma, mantle cell lymphoma and nonmelanoma skin cancer $(9,10)$. Calcineurin inhibitors (CNI) such as cyclosporine and tacrolimus appear to independently promote cancer progression/aggressive behavior by increasing levels of the cytokine transforming growth factor-beta (TGF- $\beta$ ) (11). CNIs may also interfere with the body's DNA repair processes thereby promoting tumor development (12).

In general, lung transplant recipients receive more immunosuppression than other SOT populations, likely contributing to the observed higher rates of cancer in this population. Other environmental risk factors such as extent of sun exposure and pre-transplant tobacco exposure also increase cancer risk $(13,14)$. Compared to the general population, SOT recipients have significantly higher risk of developing Kaposi's sarcoma, nonmelanoma skin cancers, non-Hodgkins lymphoma, liver, oral, vulvar, vaginal, anal, renal, bowel, bladder, thyroid, pancreatic and lung cancers (6). In contrast, there does not appear to be excess risk of breast or prostate cancer in the SOT population (15-17). Among recipients of lung transplants, the most common cancers are non-melanoma skin cancers, followed by lung cancer and post-transplant lymphoproliferative disorder (PTLD) (15).

Cancers after SOT most commonly develop de novo in the recipient. Tumors may also represent recurrent cancer from a pre-transplant malignancy. Rarely, tumors are donor related. Donor related disease may arise as a result of tumor transmission from a previously known or unknown malignancy in the donor, or as malignant transformation of donor cells within the recipient without a previous malignancy $(18,19)$.

\section{Donor transmitted malignancies}

Donor transmitted malignancies are extremely rare due to the rigorous donor selection criteria but remain a concern as the severe shortage of organs and high waitlist mortality has led many transplant centers to consider organs from extended-criteria donors (20-22). The incidence of donor transmitted tumors appears to be low and reported to be between $0.01-0.05 \%(21,23,24)$. In 2008 , the United States Organ Procurement and Transplantation Network/ United Network for Organ Sharing (OPTN/UNOS) established a subcommittee to review the impact and risk of donor-related malignancy transmission. Their report was published in 2011 (25). Although they found that high level evidence was not available to precisely determine cancer transmission risks, estimates could be determined. The reports suggested that certain cancers (e.g., basal cell skin carcinoma, in situ cervical carcinoma, solitary papillary thyroid cancer) posed minimal risk $(<0.1 \%)$ for transmission while other tumors had high risk $(>10 \%)$ for transmission to the organ recipient. High risk tumors include: malignant melanoma, breast cancer $>$ stage 0 , colon cancer $>$ stage 0 , choriocarcinoma, certain criteria for CNS tumors, renal cell carcinoma $>7 \mathrm{~cm}$, any metastatic cancer and prior history of melanoma, leukemia, lymphoma, small cell lung/ neuroendocrine tumors. Other cancers were designated as low or intermediate risk (25). Ultimately, the decision to accept a donor with a known or possible history of cancer depends on the potential transplant candidate's severity of illness, likelihood of survival until another donor is identified, individual transplant center's assessment of risk and patient willingness to consider these types of donors.

\section{Common malignancies after lung transplant:}

\section{Skin cancer}

Nonmelanoma skin cancers are the most common malignancies in SOT recipients including after lung transplantation $(14,26)$. They account for up to $50 \%$ of all cancers reported in the post-transplant population. Squamous cell carcinoma (SCC), is the most common with a 100-200-fold increased risk compared to the general population (14). The incidence of basal cell carcinoma (BCC) is comparatively low with reports showing a 4-10fold increased risk thus the BCC to SCC ratio which is 
approximately 4:1 in immunocompetent populations, is reversed in SOT recipients. Recent studies have reported an incidence of $11.4 \%$ for BCC and $26.5 \%$ for SCC at ten years' post-transplant $(27,28)$. Merkel cell carcinoma is a rare, aggressive nonmelanoma skin cancer of neuroendocrine origin that is 24 -fold more common in transplant recipients (29). Compared to the general population, non-melanoma skin cancers develop at a younger age, behave more aggressively, often developing at multiple sites with frequent local recurrences and higher rates of metastatic disease and mortality $(17,28)$.

SOT recipients are also at increased risk for malignant melanoma. A recent analysis reported a relative risk of 2.7 compared to non-transplant patients (27). Although donor transmission of cancer is rare, melanoma is one of the more commonly reported donor derived malignancies. In fact, presentation many years after transplantation has been described with one case report describing donor transmitted melanoma presenting in a lung transplant recipient more than 30 -years after resection in the donor $(18,30,31)$.

\section{Risk factors}

The increased risk for non-melanoma skin cancer in SOT recipients is primarily attributed to immunosuppression. Among SOT recipients, lung transplant patients generally require treatment with the highest level of immunosuppression. Thus, it's not surprising that rates of nonmelanoma skin cancer and death from this malignancy are highest after lung transplantation (14). Infections with oncogenic viruses likely play an important role as well with some studies reporting that the majority of squamous skin cancers in the transplant population are associated with HPV infection (32). Other reported risk factors for both melanoma and nonmelanoma skin cancers include male sex and increased age at transplantation $(14,27,28,33)$. High sun exposure and fair skin are known risk factors for nonmelanoma skin cancer $(28,34)$.

Recently, increasing use of the antifungal medication voriconazole to treat or prevent aspergillus and other fungal infections has been reported to increase risk of squamous cell skin cancer in transplant recipients (35-37). In a multicenter, international, retrospective cohort study of 900 lung transplant recipients, voriconazole exposure $>30$ days was identified as an independent risk factor for squamous cell cancer [hazard ratio $(\mathrm{HR})=2.4$ ]. Increased dose and duration of voriconazole treatment was associated with greater risk. In particular, treatment for more than 180-days had an adjusted HR of 3.5 for squamous cell cancer (37). Voriconazole has been associated with several acute and chronic phototoxic reactions and actinic keratosis. However, the mechanism by which this agent increases skin cancer risk is not well understood. Its major metabolite, voriconazole $\mathrm{N}$-oxide (VNO) may sensitize keratinocytes to ultraviolet A radiation and generate toxic reactive oxygen species that damages cellular DNA $(38,39)$.

\section{Prevention}

All patients should receive education on the high risk of developing skin cancer after transplantation and strategies to mitigate this risk. On routine follow up visits, the physician should emphasize the importance of limiting sun exposure and provide education on use of protective clothing and application of high sun protection factor (SPF) sunscreen while outdoors $(27,40,41)$. At minimum, routine annual consultation with a transplant dermatologist for skin surveillance is recommended (42). Patients with multiple risk factors may need more frequent evaluation $(40,41)$.

With increasing evidence that voriconazole may increase risk of squamous cell skin cancers, shorter courses of therapy or use of alternative agents should be considered. Additionally, in high risk patients, the overall level of immunosuppression should be minimized if possible. A recent retrospective study in lung transplant recipients suggested that switching azathioprine to MMF was associated with lower rates of skin cancer (7). Systemic treatment with chemoprophylactic agents such as retinoids (e.g., acitretin), nicotinamide and capecitabine may be recommended for very high-risk patients. Other preventative approaches include treatment with topical immunomodulatory agents such as imiquimod, 5-fluorouracil cream, diclofenac gel and photodynamic therapy directed to high risk areas (areas with many actinic keratosis/squamous cell carcinomas in situ). While several reports are encouraging, additional investigation is required to better understand risks, efficacy and duration of therapy, especially given high concern for relapse when treatment is stopped (41). Notably, data specific to the lung transplant population is lacking.

\section{Treatment}

Treatment for skin cancer in lung transplant recipients is similar to nontransplant populations and centers on excision of the cancer, typically employing the Mohs micrographic surgical approach to preserve uninvolved tissue. Wide surgical excision may also be considered. Immunosuppressed recipients have increased risk of complications after excision including surgical site infections 
and wound dehiscence (43). If possible, immunosuppression should be reduced to diminish risk for cancer recurrence and surgical complications. As some studies report that an immunosuppression regimen employing mTOR inhibitors (e.g., sirolimus) with a dose reduction of CNIs is associated with lower rates of skin cancer, this approach should also be contemplated, yet balanced with possible adverse effects, including impaired wound healing (28).

For inoperable tumors and patients deemed to be at prohibitively high risk for surgery, radiation therapy may be recommended (44). Therapeutic options for locally advanced or metastatic disease are limited. Systemic treatment with epidermal growth factor receptor (EGFR) inhibitors may be appropriate for select patients. Recently, treatment with cemiplimab, a high-affinity, highly potent human monoclonal antibody directed against programmed death 1 (PD-1) was approved for the treatment of advanced cutaneous squamous cell cancer (45). However, this approach has not been studied in transplant recipients and there is significant concern that immunotherapeutic approaches that inhibit PD-1 will increase risk of graft rejection.

\section{Lung cancer}

Lung cancer is more commonly seen in SOT recipients than the general population, with the greatest risk in lung transplantation followed by heart, liver and kidney transplantation $(15,46)$. Lung transplant recipients appear to have up to a 5-fold increased risk of lung cancer compared to the general population, with reported incidence ranging from $1-9 \%(47,48)$. Chronic obstructive pulmonary disease (COPD) and interstitial lung disease are the leading indications for lung transplant; both conditions are independently associated with lung cancer (2). Similar to the general population, significant pre-transplant exposure to carcinogenic toxins (e.g., cigarette smoke), older age and male gender have been reported to increase risk of lung cancer after transplantation. Single lung recipients appear to be at highest risk for lung cancer as this procedure necessarily leaves behind a native lung exposed to these conditions (15,47-51). While early stage lung cancer has a better prognosis than presentation at later stages, a recent report from the US Scientific Registry for Transplant (SRTR) found that outcomes in lung transplant recipients is generally poorer than lung cancer treated in the general population even though detection at earlier stages and surgical resection is more common (48). Poorer outcomes in the transplant population likely reflect the deleterious effects of immunosuppression on promoting aggressive tumor behavior and metastasis.

\section{Clinical presentation}

Lung cancer may be seen in four distinct clinical situations after lung transplantation: (I) lung cancer in the native lung after single lung transplantation; (II) incidental detection of lung cancer in the explanted diseased lung; (III) lung cancer development in the allograft (donor transmitted or de novo malignancy); and (IV) recurrence in a patient transplanted for the primary indication of lung cancer.

As mentioned previously, most cases of lung cancer in lung transplant recipients arise in the native lung of single lung transplant recipients. The recent SRTR report indicates a 13 -fold higher rate in this group compared to the general population $(15,48)$. Prevalence rates ranging from $1.5-8.9 \%$ have been reported $(52,53)$. In contrast, lung cancer in the allograft after single or bilateral lung transplantation is very uncommon (49). This is likely due to the careful donor selection process. However, as the extreme shortage of donor organs persists, transplant centers are increasingly utilizing extended-donors who may be older and have a more extensive smoking history. It remains to be seen if this will impact the future incidence of lung cancer in the allograft $(20,48,49,54,55)$.

Recipient pre-transplant screening with chest CT scan has made tumor detection in the explanted lungs an unusual finding. Incidence ranges from $0.8-2 \%$ in various studies $(56,57)$ with adenocarcinoma being the most frequent histologic type (52). Prognosis in these patients is stage dependent. Early stage I cancer has a more favorable prognosis, while most patients diagnosed with nodal involvement, stage II or III disease, experience recurrence and die within a year $(33,52,56,57)$. Recent history of malignancy is generally considered an absolute contraindication to lung transplantation, with a $2-$ to 5 -year disease free interval recommended for many types of cancers prior to listing (58). At present, there are no consensus guidelines for lung cancer screening for candidates on the wait list with many centers employing an approach similar to what is recommended in the general population with annual Chest CT scans in high risk populations $(59,60)$. Detecting lung cancer before transplantation can be challenging as many abnormalities on CT imaging may represent inflammatory or infectious processes rather than malignancy. Lung cancer arising in the background of interstitial changes may be difficult to recognize. Furthermore, imaging modalities such as 
positron emission tomography (PET) scanning can have high false positive rates. Obtaining diagnostic tissue requires invasive procedures that may be especially dangerous in tenuous patients with limited respiratory reserve (56).

Development of de novo lung cancer in the allograft is relatively uncommon. Prevalence ranges from $0.3-1.8 \%$ $(52,56)$. Lung cancer in the allograft often raises concern about donor transmission, especially if it occurs in the months immediately following transplantation. De novo tumors, however, may be of either donor or recipient origin and seen even after bilateral lung transplantation $(61,62)$.

Lung adenocarcinoma in situ (AIS) and minimally invasive adenocarcinoma (MIA) with predominant or pure lepidic patterns, entities previously known as bronchoalveolar carcinoma (BAC), are a subset of lung adenocarcinoma without evidence of stromal, pleural or lymphatic invasion. Select patients with this diagnosis may be considered for lung transplantation $(58,63)$. Several studies that specifically evaluated transplantation outcomes of patients with BAC demonstrated that while post-transplant recurrence rates were high for diffuse disease, impact on long-term survival was mixed $(64,65)$. However, these studies utilized now outdated nomenclature that lumped together all patients with BAC. The recent re-classification of BAC into subtypes by histology and molecular criteria has identified distinct subgroups with different outcomes $(57,58)$. Thus, it's possible that outcomes after lung transplantation could be better for certain subtypes (e.g., AIS) but additional studies are needed to confirm this hypothesis (57).

\section{Treatment}

Regardless of tumor origin, treatment of lung cancer after transplantation is challenging. Immunosuppression is typically reduced if deemed to be safe. Use of an immunosuppression regimen that includes an mTOR inhibitor may be considered as this class of immunosuppressive drugs has potential antineoplastic effects. Their impact in treatment of nonsmall cell lung cancer (NSCLC), however, is not clear $(66,67)$. Unfortunately, many transplant recipients have significant co-morbidities or poor pulmonary reserve that limits consideration of definitive therapy with surgical resection or treatment with chemotherapy and/or radiation (56). Over the last few years, treatment with immune checkpoint inhibitors, have emerged as an important therapeutic option for advanced NSCLC with recent data showing improved overall survival (68). Unfortunately, these drugs have not been well studied in the post-transplant setting and the limited available data raises significant concern that the primary mechanism of action of these medications to enhance antitumor immune effects may have the unintended consequence of increasing alloreactivity and promote accelerated graft loss (69-71). Further study is needed to determine safety and efficacy before definitive recommendations regarding these medications can be established.

The best preventative measures for lung cancer are related to risk factor modification. Smoking cessation is mandatory for lung transplant candidacy and treatment groups should confirm abstinence post-transplant. High rates of cancer in the native lung in single lung transplant have led some authors to favor double vs. single lung transplant (52). However, this approach should be considered carefully as unintended consequences may cause greater harm by limiting organ availability and increased waiting times resulting in greater likelihood of clinical decline and mortality for the overall waitlisted patient population (72).

\section{PTLD}

The term PTLD represents a heterogeneous group of lymphoid disorders that includes benign polyclonal B-cell proliferation and monoclonal malignancies such as diffuse large-B cell lymphoma. It is one of the most common cancers seen in organ transplant recipients with intestinal and lung transplant recipients reported to be at greatest risk $(15,73)$. Most cases of PTLD are associated with EBV-infection with higher risk in the lung transplant population likely related to the large amount of passenger lymphoid tissue in the allograft containing latent EBV infected donor B-lymphocytes and the relative increased intensity of the post-transplant immunosuppression regimen. Post-transplant immunosuppression impairs T-cell-specific immunity against EBV and increases the likelihood of developing lymphoma. Notably, multiple studies have shown an association between lymphoma onset and induction with OKT3 (humanized anti CD3) which is no longer used (13). Anti-thymocyte globulin (ATG) and alemtuzumab (anti CD52) which are also lymphocyte depleting agents, have been shown in some studies to be associated with lymphoma development. Non depleting agents such as basiliximab and daclizumab (IL-2 receptor antagonists) have not been associated with increased risk for PTLD (73-77).

The incidence of PTLD after lung transplantation has been reported to be between $3-9 \%$ and is associated with worse long-term survival and high mortality $(78,79)$. 
Transplant recipients without prior exposure to EBV who receive an organ from a donor with history of EBV infection are more likely to develop PTLD and have severe disease. Thus, it's not surprising that pediatric patients are at greatest risk $(13,80)$. While PTLD most commonly arises from EBV infected B cells (85\%), it may develop from T-cells, natural killer cells and plasma cells (81). EBV-negative PTLD is also increasingly recognized. Its pathogenesis is not well understood (82).

\section{Clinical presentation}

PTLD can develop at any time point after transplantation. The majority of cases ( $60 \%)$ develop "early" or in the first post-transplant year with the remaining cases designated as "late-onset" PTLD (81). Early onset PTLD is typically seen in children and adults who have not had prior EBV infection and acquire the infection from the donor. Thus, early PTLD is seen to develop more commonly in the allograft. Studies suggest that this type of PTLD is more likely to respond to reduction in immunosuppression (83). In contrast, late onset PTLD, is seen more commonly in extrathoracic locations (e.g., intestinal tract and lymph node tissue) is disseminated and more likely to be an EBV negative tumor. Late-onset PTLD is generally associated with worse prognosis $(73,78,79,84)$.

\section{Treatment/prognosis}

Treatment approaches generally involve reduction of immunosuppression to enhance cell-mediated immune response against EBV-infected cells, administration of anti-B-cell agents such as rituximab and/or cytotoxic chemotherapy drugs, consideration of surgical resection or radiation therapy for localized disease and perhaps immunotherapeutic approaches such as the infusion EBVspecific cytotoxic T-lymphocytes for disease refractory to other approaches (81).

Immunosuppression reduction alone has a response rate of up to $45 \%$ in SOT (85). Unfortunately, this approach is associated with significant risk for rejection and graft loss $(78,85)$. In fact, in some reports, CLAD rather than PTLD related death, was the leading cause of mortality in lung recipients with PTLD (74).

In practice, immunosuppression reduction usually involves discontinuing the cell cycle inhibitor (e.g., MMF, azathioprine), lowering CNI target serum trough levels and decreasing corticosteroid dosing while monitoring graft function closely $(77,86)$. The next line of therapy after immunosuppression reduction is treatment with the chimeric anti-CD20 monoclonal antibody rituximab. CD20 is present on the surface of both normal and malignant B-cells. Rituximab binding to these cells induces cell death. Response rates have ranged between $44-66 \%$ in various studies and rituximab may be used in isolation, in conjunction with immunosuppression reduction or in combination with more traditional cytotoxic chemotherapeutic agents $(73,79,87)$. More recently, there has been interest in developing targeted immunotherapies to treat PTLD. Approaches that are currently being explored include ex vivo expansion and adoptive transfer of autologous EBV-specific cytotoxic T-lymphocytes into the transplant recipient. Further study is needed to determine the safety and efficacy of these approaches (88-90).

PTLD is associated with a worse overall and CLAD free survival compared to thoracic organ transplant recipients without PTLD. Poorer prognosis is associated with reduced performance status, disseminated disease and disease location. EBV-negative tumors and late-onset disease generally has worse outcomes $(73,78,91-93)$. A recent meta-analysis of PTLD in lung transplant recipients demonstrated a significantly lower risk of death in double lung transplant recipients compared to single-lung recipients. However, confounding factors such as age, indication for transplantation, severity of pre-transplant illness, frailty, intensity of immunosuppression could not be adjusted for. Thus, further study is needed to determine if double lung transplantation is independently associated with a survival advantage in patients with PTLD (79).

\section{Prevention}

Strategies to prevent PTLD are limited and center on early detection of EBV viremia in high risk (e.g., EBV-naive) patients. Low levels of viremia can be identified through polymerase chain reaction (PCR)-based approaches. Several reports have shown that high or increasing EBV viral loads often precede the development of PTLD (94-96). If detected, pre-emptive reduction in immunosuppression could be considered to potentially avert PTLD development (97). For transplant recipients deemed to be at high risk for graft rejection, empiric treatment for possible PTLD with rituximab in the setting of persistent EBV viremia has been considered with reports suggesting safety and benefit $(98,99)$. While initial studies raised hope that high-risk patients treated with anti-viral prophylaxis (e.g., ganciclovir) would have lower risk of PTLD development, a recent meta-analysis reported that there was no difference in rates of PTLD development between those who received 
anti-viral prophylaxis and those that did not (100-102).

\section{Other malignancies}

An analysis of the United States Scientific Registry of Transplant Recipients (SRTR) showed lower rates of breast and prostate cancer compared to the general population. This somewhat unexpected finding is likely due to the intensive screening for malignancies transplant candidates are required to undergo before transplantation with detection of cancer excluding patients from transplantation or necessitating treatment and extended cancer-free survival before transplantation (15). Other contemporary reports did not find lower rates highlighting the importance of maintaining rigorous screening after transplantation $(103,104)$. As survival after transplantation increases, the rates of these cancers are expected to increase further. Once these cancers develop, there is concern that they may behave more aggressively and have poorer outcome $(103,105)$.

Solid organ transplant recipients are at increased risk for colorectal cancer $(15,106)$. In particular, lung transplant recipients with cystic fibrosis (CF) appear to be at especially high risk. Specific guidelines for colorectal screening among CF patients have been developed and should be followed during the transplant evaluation and post-transplant phases of care $(15,106,107)$. At present, there is no consensus regarding malignancy screening for solid-organ transplant recipients. The American Society of Transplantation recently reviewed the recommendations from different societies for various cancers (108).

\section{Conclusions}

Post-transplant immunosuppression increases the risk of many different types of cancer. As early outcomes have continued to improve, malignancy has emerged as an important obstacle to long term survival and quality of life. Patient education about these risks, adherence to general screening protocols and closer attention to certain high-risk cancers is essential. In the future, enhanced understanding of how immunosuppression increases malignancy risk, development of novel diagnostic tools that allow for early detection and targeted treatments may improve malignancy related outcomes.

\section{Acknowledgments}

Funding: None.

\section{Footnote}

Provenance and Peer Review: This article was commissioned by the Guest Editors (Masaaki Sato and Dong Tian) for the series "Strategies to Achieve Long-Term Success of Lung Transplantation" published in Annals of Translational Medicine. The article was sent for external peer review organized by the Guest Editors and the editorial office.

Conflicts of Interest: The series "Strategies to Achieve LongTerm Success of Lung Transplantation" was commissioned by the editorial office without any funding or sponsorship. The authors have no other conflicts of interest to declare.

Ethical Statement: The authors are accountable for all aspects of the work in ensuring that questions related to the accuracy or integrity of any part of the work are appropriately investigated and resolved.

Open Access Statement: This is an Open Access article distributed in accordance with the Creative Commons Attribution-NonCommercial-NoDerivs 4.0 International License (CC BY-NC-ND 4.0), which permits the noncommercial replication and distribution of the article with the strict proviso that no changes or edits are made and the original work is properly cited (including links to both the formal publication through the relevant DOI and the license). See: https://creativecommons.org/licenses/by-nc-nd/4.0/.

\section{References}

1. Hardy JD, Webb WR, Dalton ML Jr, et al. Lung Homotransplantation in Man: Report of the Initial Case. JAMA 1963;186:1065-74.

2. Chambers DC, Cherikh WS, Harhay MO, et al. The International Thoracic Organ Transplant Registry of the International Society for Heart and Lung Transplantation: Thirty-sixth adult lung and heart-lung transplantation Report-2019; Focus theme: Donor and recipient size match. The Journal of Heart and Lung Transplantation 2019;38:1042-55.

3. Engels EA. Cancer in Solid Organ Transplant Recipients: There Is Still Much to Learn and Do. Am J Transplant 2017;17:1967-9.

4. Cangemi M, Montico B, Fae DA, et al. Dissecting the Multiplicity of Immune Effects of Immunosuppressive Drugs to Better Predict the Risk of de novo Malignancies in Solid Organ Transplant Patients. Front Oncol 
2019;9:160.

5. Lim WH, Turner RM, Chapman JR, et al. Acute rejection, T-cell-depleting antibodies, and cancer after transplantation. Transplantation 2014;97:817-25.

6. Acuna SA. Etiology of increased cancer incidence after solid organ transplantation. Transplant Rev (Orlando) 2018;32:218-24.

7. Vos M, Plasmeijer EI, van Bemmel BC, et al. Azathioprine to mycophenolate mofetil transition and risk of squamous cell carcinoma after lung transplantation. J Heart Lung Transplant 2018;37:853-9.

8. Inman GJ, Wang J, Nagano A, et al. The genomic landscape of cutaneous SCC reveals drivers and a novel azathioprine associated mutational signature. Nat Commun 2018;9:3667.

9. de Fijter JW. Cancer and mTOR Inhibitors in Transplant Recipients. Transplantation 2017;101:45-55.

10. Maluccio M, Sharma V, Lagman M, et al. Tacrolimus enhances transforming growth factor-beta 1 expression and promotes tumor progression. Transplantation 2003;76:597-602.

11. Hojo M, Morimoto T, Maluccio M, et al. Cyclosporine induces cancer progression by a cell-autonomous mechanism. Nature 1999;397:530-4.

12. Herman M, Weinstein T, Korzets A, et al. Effect of cyclosporin A on DNA repair and cancer incidence in kidney transplant recipients. J Lab Clin Med 2001;137:14-20.

13. Rossi AP, Klein CL. Posttransplant Malignancy. Surg Clin North Am 2019;99:49-64.

14. Rashtak S, Dierkhising RA, Kremers WK, et al. Incidence and risk factors for skin cancer following lung transplantation. J Am Acad Dermatol 2015;72:92-8.

15. Engels EA, Pfeiffer RM, Fraumeni JF, Jr., et al. Spectrum of cancer risk among US solid organ transplant recipients. JAMA 2011;306:1891-901.

16. Na R, Grulich AE, Meagher NS, et al. De novo cancerrelated death in Australian liver and cardiothoracic transplant recipients. Am J Transplant 2013;13:1296-304.

17. Katabathina VS, Menias CO, Tammisetti VS, et al. Malignancy after Solid Organ Transplantation: Comprehensive Imaging Review. Radiographics 2016;36:1390-407.

18. Strauss DC, Thomas JM. Transmission of donor melanoma by organ transplantation. Lancet Oncol 2010;11:790-6.

19. Gandhi MJ, Strong DM. Donor derived malignancy following transplantation: a review. Cell Tissue Bank
2007;8:267-86.

20. Schwarz EI, Vrugt B, Huber LC, et al. Development of Allograft Cancer after Lung Transplantation: A Case Report. Ann Thorac Cardiovasc Surg 2017;23:196-9.

21. Desai R, Collett D, Watson CJ, et al. Cancer Transmission From Organ Donors-Unavoidable But Low Risk. Transplantation 2012;94:1200-7.

22. Schold JD, Segev DL. Increasing the pool of deceased donor organs for kidney transplantation. Nat Rev Nephrol 2012;8:325-31.

23. Hutchinson J. Donor Malignancies. Transplantation 2015;99:270-1.

24. Myron Kauffman H, McBride MA, Cherikh WS, et al. Transplant tumor registry: donor related malignancies. Transplantation 2002;74:358-62.

25. Nalesnik MA, Woodle ES, DiMaio JM, et al. DonorTransmitted Malignancies in Organ Transplantation: Assessment of Clinical Risk. Am J Transplant 2011;11:1140-7.

26. Berastegui C, LaPorta R, Lopez-Meseguer M, et al. Epidemiology and Risk Factors for Cancer After Lung Transplantation. Transplant Proc 2017;49:2285-91.

27. Tejwani V, Deshwal H, Ho B, et al. Cutaneous Complications in Recipients of Lung Transplants: A Pictorial Review. Chest 2019;155:178-93.

28. Grager N, Leffler M, Gottlieb J, et al. Risk Factors for Developing Nonmelanoma Skin Cancer after Lung Transplantation. J Skin Cancer 2019;2019:7089482.

29. Clarke CA, Robbins HA, Tatalovich Z, et al. Risk of merkel cell carcinoma after solid organ transplantation. J Natl Cancer Inst 2015;107.

30. Buell JF, Beebe TM, Trofe J, et al. Donor transmitted malignancies. Ann Transplant 2004;9:53-6.

31. Bajaj NS, Watt C, Hadjiliadis D, et al. Donor transmission of malignant melanoma in a lung transplant recipient 32 years after curative resection. Transpl Int 2010;23:e26-31.

32. Proby CM, Harwood CA, Neale RE, et al. A CaseControl Study of Betapapillomavirus Infection and Cutaneous Squamous Cell Carcinoma in Organ Transplant Recipients. Am J Transplant 2011;11:1498-508.

33. Olland A, Falcoz PE, Massard G. Malignancies after lung transplantation. J Thorac Dis 2018;10:3132-40.

34. Chung CL, Nadhan KS, Shaver CM, et al. Comparison of Posttransplant Dermatologic Diseases by Race. JAMA Dermatol 2017;153:552-8.

35. Elnahas S, Olson MT, Kang P, et al. Factors associated with skin cancer in lung transplant recipients: A singlecenter experience. Clin Transplant 2019;33:e13718. 
36. Tang H, Shi W, Song Y, et al. Voriconazole exposure and risk of cutaneous squamous cell carcinoma among lung or hematopoietic cell transplant patients: A systematic review and meta-analysis. J Am Acad Dermatol 2019;80:500-7.e10.

37. Hamandi B, Fegbeutel C, Silveira FP, et al. Voriconazole and squamous cell carcinoma after lung transplantation: A multicenter study. Am J Transplant 2018;18:113-24.

38. Ona K, Oh DH. Voriconazole N-oxide and its ultraviolet B photoproduct sensitize keratinocytes to ultraviolet A. British Journal of Dermatology 2015;173:751-9.

39. Kulkarni HS, Witt CA. Voriconazole in lung transplant recipients - how worried should we be? Am J Transplant 2018;18:5-6.

40. Berg D, Otley CC. Skin cancer in organ transplant recipients: Epidemiology, pathogenesis, and management. J Am Acad Dermatol 2002;47:1-17; quiz 8-20.

41. Collins L, Asfour L, Stephany M, et al. Management of Non-melanoma Skin Cancer in Transplant Recipients. Clin Oncol (R Coll Radiol) 2019;31:779-88.

42. Chan AW, Fung K, Austin PC, et al. Improved keratinocyte carcinoma outcomes with annual dermatology assessment after solid organ transplantation: Populationbased cohort study. Am J Transplant 2019;19:522-31.

43. Basu P, Goldenberg A, Cowan N, et al. A 4-year retrospective assessment of postoperative complications in immunosuppressed patients following Mohs micrographic surgery. J Am Acad Dermatol 2019;80:1594-601.

44. O'Reilly Zwald F, Brown M. Skin cancer in solid organ transplant recipients: Advances in therapy and management: Part II. Management of skin cancer in solid organ transplant recipients. J Am Acad Dermatol 2011;65:263-79.

45. Migden MR, Rischin D, Schmults CD, et al. PD-1 Blockade with Cemiplimab in Advanced Cutaneous Squamous-Cell Carcinoma. N Engl J Med 2018;379:341-51.

46. Génébès C, Brouchet L, Kamar N, et al. Characteristics of thoracic malignancies that occur after solid-organ transplantation. J Thorac Oncol 2010;5:1789-95.

47. Pérez-Callejo D, Torrente M, Parejo C, et al. Lung cancer in lung transplantation: incidence and outcome. Postgrad Med J 2018;94:15-9.

48. Triplette M, Crothers K, Mahale P, et al. Risk of lung cancer in lung transplant recipients in the United States. Am J Transplant 2019;19:1478-90.

49. Magruder JT, Crawford TC, Grimm JC, et al. Risk Factors for De Novo Malignancy Following Lung Transplantation.
Am J Transplant 2017;17:227-38

50. Raviv S, Hawkins KA, DeCamp MM Jr, et al. Lung Cancer in Chronic Obstructive Pulmonary Disease. Am J Respir Crit Care Med 2011;183:1138-46.

51. Brown SW, Dobelle M, Padilla M, et al. Idiopathic Pulmonary Fibrosis and Lung Cancer. A Systematic Review and Meta-analysis. Ann Am Thorac Soc 2019;16:1041-51.

52. Olland AB, Falcoz PE, Santelmo N, et al. Primary lung cancer in lung transplant recipients. Ann Thorac Surg 2014;98:362-71.

53. Dickson RP, Davis RD, Rea JB, et al. High frequency of bronchogenic carcinoma after single-lung transplantation. J Heart Lung Transplant 2006;25:1297-301.

54. Mulligan MJ, Sanchez PG, Evans CF, et al. The use of extended criteria donors decreases one-year survival in high-risk lung recipients: A review of the United Network of Organ Sharing Database. J Thorac Cardiovasc Surg 2016;152:891-8.e2.

55. Chaney J, Suzuki Y, Cantu E 3rd, et al. Lung donor selection criteria. J Thorac Dis 2014;6:1032-8.

56. Van Raemdonck D, Vos R, Yserbyt J, et al. Lung cancer: a rare indication for, but frequent complication after lung transplantation. J Thorac Dis 2016;8:S915-24.

57. Glanville AR, Wilson BE. Lung transplantation for nonsmall cell lung cancer and multifocal bronchioalveolar cell carcinoma. Lancet Oncol 2018;19:e351-8.

58. Weill D, Benden C, Corris PA, et al. A consensus document for the selection of lung transplant candidates: 2014--an update from the Pulmonary Transplantation Council of the International Society for Heart and Lung Transplantation. J Heart Lung Transplant 2015;34:1-15.

59. Acuna SA, Lam W, Daly C, et al. Cancer evaluation in the assessment of solid organ transplant candidates: A systematic review of clinical practice guidelines. Transplant Rev (Orlando) 2018;32:29-35.

60. Hoffman RM, Sanchez R. Lung Cancer Screening. Med Clin North Am 2017;101:769-85.

61. Picard C, Grenet D, Copie-Bergman C, et al. Small-cell lung carcinoma of recipient origin after bilateral lung transplantation for cystic fibrosis. J Heart Lung Transplant 2006;25:981-4.

62. Brand T, Haithcock B. Lung Cancer and Lung Transplantation. Thoracic Surgery Clinics 2018;28:15-8.

63. de Perrot M, Chernenko S, Waddell TK, et al. Role of Lung Transplantation in the Treatment of Bronchogenic Carcinomas for Patients With End-Stage Pulmonary Disease. J Clin Oncol 2004;22:4351-6. 


\section{Page 10 of 11}

64. Ahmad U, Wang Z, Bryant AS, et al. Outcomes for Lung Transplantation for Lung Cancer in the United Network for Organ Sharing Registry. Ann Thorac Surg 2012;94:935-40.

65. Zorn GL Jr, McGiffin DC, Young KR Jr, et al. Pulmonary transplantation for advanced bronchioloalveolar carcinoma. J Thorac Cardiovasc Surg 2003;125:45-8.

66. Tian T, Li X, Zhang J. mTOR Signaling in Cancer and mTOR Inhibitors in Solid Tumor Targeting Therapy. Int J Mol Sci 2019;20:755.

67. Vicary GW, Roman J. Targeting the Mammalian Target of Rapamycin in Lung Cancer. Am J Med Sci 2016;352:507-16.

68. Assi HI, Kamphorst AO, Moukalled NM, et al. Immune checkpoint inhibitors in advanced non-small cell lung cancer. Cancer 2018;124:248-61.

69. Fisher J, Zeitouni N, Fan W, et al. Immune checkpoint inhibitor therapy in solid organ transplant recipients: A patient-centered systematic review. J Am Acad Dermatol 2019. [Epub ahead of print].

70. Abdel-Wahab N, Safa H, Abudayyeh A, et al. Checkpoint inhibitor therapy for cancer in solid organ transplantation recipients: an institutional experience and a systematic review of the literature. J Immunother Cancer 2019;7:106.

71. Smedman TM, Line PD, Guren TK, et al. Graft rejection after immune checkpoint inhibitor therapy in solid organ transplant recipients. Acta Oncologica 2018;57:1414-8.

72. Nathan SD, Shlobin OA, Ahmad S, et al. Comparison of wait times and mortality for idiopathic pulmonary fibrosis patients listed for single or bilateral lung transplantation. J Heart Lung Transplant 2010;29:1165-71.

73. Neuringer IP. Posttransplant lymphoproliferative disease after lung transplantation. Clin Dev Immunol 2013;2013:430209.

74. Muchtar E, Kramer MR, Vidal L, et al. Posttransplantation lymphoproliferative disorder in lung transplant recipients: a 15-year single institution experience. Transplantation 2013;96:657-63.

75. Hertig A, Zuckermann A. Rabbit antithymocyte globulin induction and risk of post-transplant lymphoproliferative disease in adult and pediatric solid organ transplantation: An update. Transpl Immunol 2015;32:179-87.

76. Swinnen LJ, Costanzo-Nordin MR, Fisher SG, et al. Increased incidence of lymphoproliferative disorder after immunosuppression with the monoclonal antibody OKT3 in cardiac-transplant recipients. N Engl J Med 1990;323:1723-8.

77. Paya CV, Fung JJ, Nalesnik MA, et al. Epstein-Barr virus-

\section{Shtraichman and Ahya. Malignancy after lung transplantation}

induced posttransplant lymphoproliferative disorders. ASTS/ASTP EBV-PTLD Task Force and The Mayo Clinic Organized International Consensus Development Meeting. Transplantation 1999;68:1517-25.

78. Leyssens A, Dierickx D, Verbeken EK, et al. Posttransplant lymphoproliferative disease in lung transplantation: A nested case-control study. Clin Transplant 2017;31.

79. Cheng J, Moore CA, Iasella CJ, et al. Systematic review and meta-analysis of post-transplant lymphoproliferative disorder in lung transplant recipients. Clin Transplant 2018;32:e13235.

80. Shapiro R, Nalesnik M, McCauley J, et al. Posttransplant lymphoproliferative disorders in adult and pediatric renal transplant patients receiving tacrolimus-based immunosuppression. Transplantation 1999;68:1851-4.

81. Nagle SJ, Reshef R, Tsai DE. Posttransplant Lymphoproliferative Disorder in Solid Organ and Hematopoietic Stem Cell Transplantation. Clin Chest Med 2017;38:771-83.

82. Luskin MR, Heil DS, Tan KS, et al. The Impact of EBV Status on Characteristics and Outcomes of Posttransplantation Lymphoproliferative Disorder. Am J Transplant 2015;15:2665-73.

83. Campo E, Swerdlow SH, Harris NL, et al. The 2008 WHO classification of lymphoid neoplasms and beyond: evolving concepts and practical applications. Blood 2011;117:5019-32.

84. Zafar SY, Howell DN, Gockerman JP. Malignancy after solid organ transplantation: an overview. Oncologist 2008;13:769-78.

85. Reshef R, Vardhanabhuti S, Luskin MR, et al. Reduction of immunosuppression as initial therapy for posttransplantation lymphoproliferative disorder( bigstar). Am J Transplant 2011;11:336-47.

86. Parker A, Bowles K, Bradley JA, et al. Management of post-transplant lymphoproliferative disorder in adult solid organ transplant recipients - BCSH and BTS Guidelines. Br J Haematol 2010;149:693-705.

87. Trappe R, Oertel S, Leblond V, et al. Sequential treatment with rituximab followed by CHOP chemotherapy in adult B-cell post-transplant lymphoproliferative disorder (PTLD): the prospective international multicentre phase 2 PTLD-1 trial. Lancet Oncol 2012;13:196-206.

88. Bollard CM, Rooney CM, Heslop HE. T-cell therapy in the treatment of post-transplant lymphoproliferative disease. Nat Rev Clin Oncol 2012;9:510-9.

89. Savoldo B, Goss JA, Hammer MM, et al. Treatment of 
solid organ transplant recipients with autologous Epstein Barr virus-specific cytotoxic T lymphocytes (CTLs). Blood 2006;108:2942-9.

90. Kim N, Sohn HJ, Oh JH, et al. Infusions of Epstein-Barr virus-specific cytotoxic $\mathrm{T}$ lymphocytes as post-remission therapy in high-risk post-transplant lymphoproliferative disorder patients: report of two cases. Int J Hematol 2018;107:596-603.

91. Kumarasinghe G, Lavee O, Parker A, et al. Posttransplant lymphoproliferative disease in heart and lung transplantation: Defining risk and prognostic factors. J Heart Lung Transplant 2015;34:1406-14.

92. Ramalingam P, Rybicki L, Smith MD, et al. Posttransplant lymphoproliferative disorders in lung transplant patients: the Cleveland Clinic experience. Mod Pathol 2002;15:647-56.

93. Verschuuren EA, Popa ER, Van Der Bij W, et al. Donor or recipient origin of post transplant lymphoproliferative disease after lung transplantation. J Heart Lung Transplant 2001;20:199.

94. Riddler SA, Breinig MC, McKnight JL. Increased levels of circulating Epstein-Barr virus (EBV)-infected lymphocytes and decreased EBV nuclear antigen antibody responses are associated with the development of posttransplant lymphoproliferative disease in solid-organ transplant recipients. Blood 1994;84:972-84.

95. Baldanti F, Grossi P, Furione M, et al. High levels of Epstein-Barr virus DNA in blood of solid-organ transplant recipients and their value in predicting posttransplant lymphoproliferative disorders. J Clin Microbiol 2000;38:613-9.

96. Baldanti F, Rognoni V, Cascina A, et al. Post-transplant lymphoproliferative disorders and Epstein-Barr virus DNAemia in a cohort of lung transplant recipients. Virol J 2011;8:421.

97. Lee TC, Savoldo B, Rooney CM, et al. Quantitative EBV viral loads and immunosuppression alterations can decrease PTLD incidence in pediatric liver transplant recipients. Am J Transplant 2005;5:2222-8.

98. Choquet S, Varnous S, Deback C, et al. Adapted treatment of Epstein-Barr virus infection to prevent posttransplant lymphoproliferative disorder after heart transplantation. Am J Transplant 2014;14:857-66.

99. van Esser JW, Niesters HG, van der Holt B, et al. Prevention of Epstein-Barr virus-lymphoproliferative disease by molecular monitoring and preemptive rituximab in high-risk patients after allogeneic stem cell transplantation. Blood 2002;99:4364-9.

100.AlDabbagh MA, Gitman MR, Kumar D, et al. The Role of Antiviral Prophylaxis for the Prevention of EpsteinBarr Virus-Associated Posttransplant Lymphoproliferative Disease in Solid Organ Transplant Recipients: A Systematic Review. Am J Transplant 2017;17:770-81.

101.Funch DP, Walker AM, Schneider G, et al. Ganciclovir and acyclovir reduce the risk of post-transplant lymphoproliferative disorder in renal transplant recipients. Am J Transplant 2005;5:2894-900.

102. Malouf MA, Chhajed PN, Hopkins P, et al. Anti-viral prophylaxis reduces the incidence of lymphoproliferative disease in lung transplant recipients. J Heart Lung Transplant 2002;21:547-54.

103. Wong G, Au E, Badve SV, et al. Breast Cancer and Transplantation. Am J Transplant 2017;17:2243-53.

104. Oh SC, Tariq MB, Reddy CA, et al. Outcomes in Organ Transplant Recipients With Prostate Cancer Treated With Radiotherapy. Clin Genitourin Cancer 2019;17:e162-6.

105. Kleinclauss F, Gigante M, Neuzillet Y, et al. Prostate cancer in renal transplant recipients. Nephrol Dial Transplant 2008;23:2374-80.

106. Safaeian M, Robbins HA, Berndt SI, et al. Risk of Colorectal Cancer After Solid Organ Transplantation in the United States. Am J Transplant 2016;16:960-7.

107. Hadjiliadis D, Khoruts A, Zauber AG, et al. Cystic Fibrosis Colorectal Cancer Screening Consensus Recommendations. Gastroenterology 2018;154:736-45 e14.

108. Acuna SA, Huang JW, Scott AL, et al. Cancer Screening Recommendations for Solid Organ Transplant Recipients: A Systematic Review of Clinical Practice Guidelines. Am J Transplant 2017;17:103-14.
Cite this article as: Shtraichman O, Ahya VN. Malignancy after lung transplantation. Ann Transl Med 2020;8(6):416. doi: 10.21037/atm.2020.02.126 